\title{
Pengaruh Penambahan Oksidator Kalium Bichromat pada Pengambilan Minyak Laka
}

\author{
Harsa Pawignya \\ Jurusan Teknik Kimia, Fakultas Teknologi Industri UPN "Veteran” Yogyakarta \\ Jl. SWK 104 (Lingkar Utara), Yogyakarta, 55283 \\ E-mail : Harsa_paw@yahoo.co.id
}

\begin{abstract}
Cashew trees have been planted in Indonesia. The yield of these trees has been utilized by many people as snack that is delicious and special, while their skin is often been thrown away, so becoming waste, although they can be utilized. Laka oil (CNSL) is a liquid in cashew skin that has economic value, such as its utilization in glue industry, varnish, synthetic resin, insecticide, fungicide, paint, brake lining and clutch plate. In this study, the taking of laka oil from cashew was conducted by using press hydraulic and soxhlet with petroleum ether solution. After obtaining laka oil, Calium Bichromate oxidator was added to improve the quality of laka oil obtained before. Variables studied were the effect of material water content, pressing pressure, the time of pressing on oil weight obtained and the number of Calium Bichromate on oil resin content. From this study, with material of 100 grams it obtained the best condition on material water content of $7,5 \%$, pressing pressure of $450 \mathrm{~kg} / \mathrm{cm}^{2}$, pressing time of 20 minuts, and the oil obtained was 8,5747 grams.
\end{abstract}

Keywords : Laka Oil

\section{Pendahuluan.}

Tanaman jambu mete banyak ditanam di Indonesia karena cara menanamnya mudah, serta buah metenya mempunyai nilai ekonomis yang berarti, mete ini biasanya dimanfaatkan sebagai makanan ringan dalam bentuk mete goreng. Sedangkan kulit mete biasanya hanya sebagai limbah, di dalam kulit mete terdapat cairan yang dikenal sebagai minyak laka (Cashew Nut Shell Liquid - CNSL), minyak laka ini dapat dimanfaatkan dalam industri perekat, vernis, memperkuat karet sintetis, resin sintetis, insektisida, fungisida, cat, kampas rem dan plat kopling (Bailey, 1951).

Pada penelitian ini akan dicoba pengambilan minyak laka dari kulit mete dengan cara pengempaan, hasil minyak yang diperoleh ditambahkan oksidator untuk menaikkan angka Iod nya sehingga akan menaikkan kualitas minyak laka yang dihasilkan. Penelitian ini bertujuan untuk mencari kondisi yang terbaik yaitu untuk pengaruh kadar air kulit mete, pengaruh tekanan dan waktu pengempaan terhadap rendemen minyak laka, serta pengaruh penambahan oksidator Kalium Bichromat terhadap kadar resin dan angka Iod minyak laka. Struktur buah mete terdiri dari :

1. Kulit buah mete glondong (pericarp)

2. Biji mete (kernel) yang dibedakan atas: Epicarp, mesocarp dan endocarp.

Mesocarp merupakan lapisan yang paling tebal dari ketiga lapisan kulit, bersifat seperti spons, mempunyai struktur yang bergelembung seperti rumah tawon yang terdiri dari jaringan sklerenkim.
Dalam lapisan ini terdapat saluran- saluran yang mengandung $32 \%$ - $37 \%$ cairan CNSL , yang bersifat lekat dan kental. . Sifat fisika dan Kimia CNSL terlihat pada table berikut :

Tabel 1. Sifat fisika dan kimia CNSL

\begin{tabular}{lcccc}
\hline & \multicolumn{4}{c}{ C N S L } \\
\cline { 2 - 5 } & mentah & masak & destilat & komersial \\
\hline B.J, 30 ${ }^{\circ} \mathrm{C}$ & - & - & - & $0,92-$ \\
Viskosita, & 400 & 435 & - & $150-460$ \\
$\mathrm{cp}$ & & & & \\
Titik didih, & - & - & 360 & - \\
${ }^{\circ} \mathrm{C}$ & & & & $8-20$ \\
Angka & - & - & - & \\
asam & & & & $220-270$ \\
Angka Iod & 269 & 254 & - & $13-30$ \\
Angka & 19,6 & 29,7 & - & \\
Safonifikasi & & & &
\end{tabular}

CNSL kasar pada umumnya mengandung $84 \%$ cardol dan sisanya $16 \%$ terdiri dari asam ancardot, asam gallat, glukosida. CNSL ini merupakan sumber phenol alam yang murah dan mempunyai manfaat yang besar dalam industri.

Pengambilan CNSL dari kulit mete :

Ada beberapa cara pengambilan CNSL dari kulit mete antara lain adalah dengan ektraksi menggunakan pelarut dan dengan cara pengepresan kulit mete. Jumlah CNSL yang diperoleh pada cara pengepresan dipengaruhi oleh:

a. Besar kecilnya ukuran bahan . 
b. Waktu penekanan .

c. Besarnya tekanan.

d. Kadar air bahan pada saat penekanan.

e. Perlakuan pendahuluan.

CNSL yang diperoleh biasanya banyak mengandung buih, adanya resin dalam minyak laka diduga sebagai sebab timbulnya buih yang banyak pada pemanasan minyak laka, dan menjadi rendahnya angka Iodida, hal ini dapat menurunkan kualitas minyak laka Ohler, 1986).

Kadar resin CNSL dapat dikurangi dengan penambahan oksidator , karena oksidator akan mencegah terjadinya reduksi asam anakardat menjadi aldehid ,sehingga reaksi kondensasi dengan phenol akan terhambat.(Prastowo, 1976). Oksidator yang dapat digunakan antara lain Kalium permanganate dan Kalium bichromat. Larutan Kalium bichromat lebih efektif dalam menghambat perubahan asam anakardat menjadi aldehid karena Kalium bichromat mempunyai konstante keseimbangan lebih besar disbanding larutan Kalium permanganate, reaksinya sebagai berikut :

$$
\begin{aligned}
& \mathrm{K}_{2} \mathrm{MnO}_{4} \longrightarrow \mathrm{K}^{+}+\mathrm{Mn} \mathrm{O}_{4}^{=} \\
& \mathrm{Mn} \mathrm{O}_{4}{ }^{=}+{ }_{8} \mathrm{H}^{+}+5 \mathrm{e} \longrightarrow \mathrm{Mn}_{(\mathrm{Eo}=1,5 \text { volt })}^{++}+{ }_{4} \mathrm{H}_{2} \mathrm{O}+\mathrm{Eo} \\
& \mathrm{K}_{2} \mathrm{Cr}_{2} \mathrm{O}_{7} \longrightarrow \mathrm{K}^{+}+\mathrm{Cr}_{2} \mathrm{O}_{7}^{=} \\
& \mathrm{Cr}_{2} \mathrm{O}_{7}{ }^{=}+{ }_{14} \mathrm{H}^{+}+6 \mathrm{e} \longrightarrow{ }_{2} \longrightarrow \mathrm{Cr}_{(\mathrm{Eo}=1,3}^{+++}+{ }_{7} \mathrm{H}_{2} \mathrm{O}+\mathrm{Eo}
\end{aligned}
$$

\section{Metodologi.}

\subsection{Bahan Baku.}

Bahan baku penelitian ini adalah kulit mete diperoleh dari daerah Berbah Yogyakarta, setelah dianalisis diperoleh kadar air 11,2\%, dengan ektraksi soxhlet diperoleh rendemen CNSL 32,96 \%. Adapun bahan untuk analisis adalah Natrium thiosulfat, asam asetat glacial, Bromin, Reagen Iodium Bromida, Larutan KI, Chloroform, Indikator pp, Indikator amilum, Kalium bichromat, alcohol 95 \%, Toluol dan Larutan $\mathrm{KOH}$.

\subsection{Peralatan Penelitian.}

Keterangan

1. Kempa hidrolik

2. Piston

3. Silinder tempat bahan.

4. Alat ukur tekanan

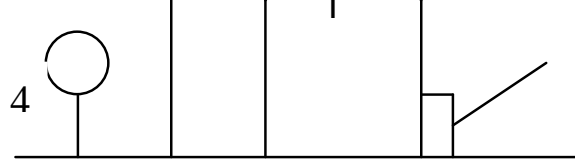

Gambar 1. Alat Percobaan

Alat lain yang digunakan adalah : Oven, eksikator, dan serangkaian soxhlet.

Kulit mete dihancurkan kemudian dipanaskan pada 60 $70{ }^{\circ} \mathrm{C}$ selama 10 menit, bahan pada keadaan panas lalu dikempa seperti pada Gambar 1. piston akan naik dan menekan bahan yang ada disilinder dan tekanan dapat dilihat pada Alat ukur tekanan, dengan variasi kadar air, tekanan dan waktu, minyak laka yang diperoleh dianalisis BJ, viskositas, angka asam, angka Iod, dan kadar resinnya.

Sebagian minyak laka yang diperoleh dari pengepresan diberi sejumlah tertentu oksidator Kalium Bichromat, kemudian dipanaskan dalam oven pada suhu $150{ }^{\circ} \mathrm{C}$ sampai buih yang terbentuk hilang, setelah dingin dianalisis kadar resin dan angka Iodnya (AOAC, 1970).

\section{Hasil dan Pembahasan}

\subsection{Pengaruh Kadar Air Bahan Baku terhadap rendemen CNSL:}

\begin{tabular}{|c|c|c|c|}
\hline No & $\begin{array}{l}\text { Kadar air } \\
\%\end{array}$ & $\begin{array}{l}\text { Berat } \\
\text { CNSL, gram }\end{array}$ & $\begin{array}{l}\text { Rendemen, } \\
\%\end{array}$ \\
\hline 1 & 11,2 & 4,8840 & 5,60 \\
\hline 2 & 8,9 & 8,0662 & 8,11 \\
\hline 3 & 7,5 & 8,5747 & 9,27 \\
\hline 4 & 5,5 & 7,3237 & 7,75 \\
\hline 5 & 3,8 & 6,3877 & 6,64 \\
\hline 6 & 2,5 & 5,5088 & 5,65 \\
\hline
\end{tabular}

Berat bahan : 100 gram

Tekanan : $450 \mathrm{~kg} / \mathrm{cm}^{2}$

Waktu : 20 menit

Tabel 1 : Hubungan antara kadar air bahan baku terhadap hasil Rendemen 


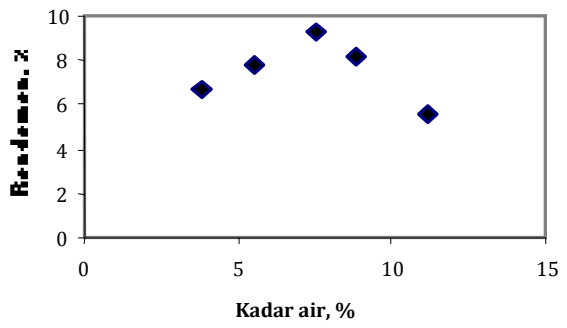

Gambar 2. Grafik hubungan Kadar air terhadap Rendemen

Dari Tabel 1 terlihat bahwa mulai kadar air 11,2\% sampai 7,5\% diperoleh rendemen yang semakin naik ,hal ini karena jumlah air yang menghalangi minyak semakin sedikit ,tetapi setelah kadar air 5,5\% diperoleh rendemen yang semakin kecil hal ini dimungkinkan pada kadar air yang rendah akan melewati batas kelembaban optimum, selain itu beberapa penyusun minyak seperti asam-asam lemak bebas dan posfatida bersifat surface aktif sehingga residu biji-bijian dapat mempunyai tendensi untuk menyerap kembali minyak yang dihasilkan (Murdijati dan Supriyanto, 1987).

\subsection{Pengaruh Tekanan pengempaan terhadap rendemen CNSL. \\ Berat bahan : 100 gram \\ Kadar air bahan : 7,5\% \\ Waktu : 20 menit}

Tabel 2 : Hubungan antara Tekanan dengan hasil Rendemen

\begin{tabular}{cccc}
\hline No & $\begin{array}{c}\text { Tekanan, } \\
\mathrm{kg} / \mathrm{cm}^{2}\end{array}$ & $\begin{array}{l}\text { Berat } \\
\text { gram }\end{array}$ & CNSL, \\
\hline 1 & 200 & 5,7350 & $\begin{array}{l}\text { Rendemen } \\
\%\end{array}$ \\
2 & 250 & 7,2242 & 6,20 \\
3 & 300 & 8,1862 & 7,81 \\
4 & 350 & 8,4637 & 8,85 \\
5 & 400 & 8,5747 & 9,15 \\
6 & 450 & 8,5748 & 9,27 \\
7 & 475 & 8,5100 & 9,27 \\
8 & 500 & 8,5250 & 9,20 \\
\hline
\end{tabular}

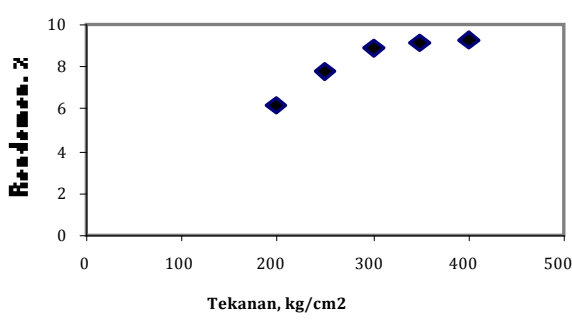

Gambar 3. Grafik hubungan Tekanan dengan Rendemen

Dari Tabel 2 terlihat makin besar tekanan diperoleh rendemen yang semakin banyak, hal ini disebabkan karena semakin besar tekanan maka minyak akan semakin mudah keluar dari bahan bakunya.

\subsection{Pengaruh Waktu pengempaan terhadap rendemen CNSL.}



Tabel 3 : Hubungan antara Waktu pengempaan terhadap hasil Rendemen

\begin{tabular}{cccc}
\hline No & $\begin{array}{c}\text { Waktu, } \\
\text { menit }\end{array}$ & $\begin{array}{l}\text { Berat, } \\
\text { gram }\end{array}$ & $\begin{array}{l}\text { Rendemen, } \\
\%\end{array}$ \\
\hline 1 & 5 & 5,3650 & 5,80 \\
2 & 10 & 7,5850 & 8,20 \\
3 & 15 & 8,0475 & 8,70 \\
4 & 20 & 8,5747 & 9,27 \\
5 & 25 & 8,5748 & 9,28 \\
6 & 30 & 8,5747 & 9,27 \\
\hline
\end{tabular}



Gambar 4. Grafik hubungan waktu ekstraksi terhadap Rendemen

Dari Tabel 3, terlihat bahwa semakin lama waktu pengempaan maka rendemen yang dihasilkan semakin banyak, tetapi setelah waktu 20 menit ternyata rendemen yang dihasilkan relative konstan, karena pada keadaan tersebut minyak yang dihasilkan sudah maksimum, 
sedang sisa minyak yang lain sudah terperangkap di dalam ampasnya sehingga penambahan waktu pengempaan sudah tidak berpengaruh lagi.

\subsection{Pengaruh Penambahan Oksidator Kalium Bichromat terhadap Kadar Resin dan Angka Iod.}

Tabel 4 : Hubungan antara Kadar Kalium Bichromat terhadap Kadar Resin dan Angka Iod

\begin{tabular}{|c|c|c|c|}
\hline No & $\begin{array}{l}\mathrm{K}_{2} \mathrm{Cr}_{2} \mathrm{O}_{7} \\
\mathrm{mg}\end{array}$ & $\begin{array}{l}\text { Kadar Resin, } \\
\% \mathrm{w} / \mathrm{w}\end{array}$ & Angka Iod \\
\hline 1 & 0 & 11,33 & 242,8971 \\
\hline 2 & 1 & 11,12 & 243,1871 \\
\hline 3 & 2,5 & 9,70 & 244,7882 \\
\hline 4 & 5 & 8,89 & 247,1235 \\
\hline 5 & 7,5 & 8,50 & 249,3025 \\
\hline 6 & 10 & 8,10 & 250,8245 \\
\hline 7 & 12,5 & 8,10 & 250,8245 \\
\hline
\end{tabular}

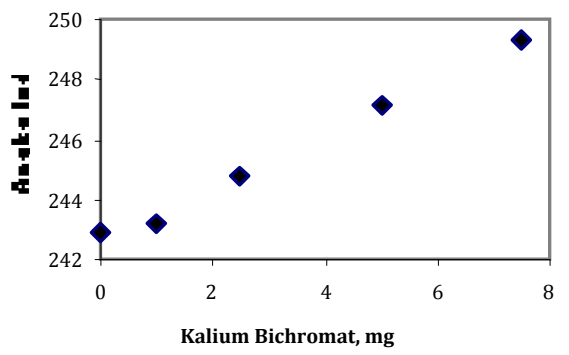

Gambar 5. Grafik hubungan Kadar Kalium Bichromat terhadap Angka Iod.

Dari Tabel 4 terlihat semakin banyak oksidator yang ditambahkan maka semakin rendah kadar resinnya tetapi semakin tinggi angka Iod nya, hal ini disebabkan penambahan oksidator akan menghambat terjadinya kondensasi dari phenol yang terkandung dalam minyak laka yaitu : cardol, anacardol dan cardanol. Kandungan minyak laka yang dominant adalah asam anacardat (90\%), kemungkinan asam ini tereduksi menjadi aldehid pada pemanasan (Prastowo, 1976), maka reaksi reduksi asam anacaedat menjadi aldehid akan terhambat dengan penambahan oksidator.

Pengurangan kadar resin akan menaikkan angka Iod minyak laka, karena dengan terpacunya asam anacardat akan terhambat sehingga pembentukan resin dari hasil kondensasi aldehid dan phenol juga terhambat. Dengan adanya kardanol dalam CNSL akan mengikat Iod pada pengujian angka Iod, sehingga dengan makin banyaknya kardanol terbentuk angka Iod akan naik, tetapi kardanol yang dapat dibentuk tergantung dari asam anakardat yang ada sehingga angka Iod akan konstan setelah kardanol setara dengan asam anakardat yang dikandung dalam CNSL.

\section{Kesimpulan.}

1. Kondisi yang relatif baik untuk pengambilan CNSL dari bahan baku 100 gram dengan pengempaan adalah pada : kadar air bahan 7,5 $\%$, tekanan $450 \mathrm{~kg} / \mathrm{cm}^{2}$, waktu pengepresan 20 menit diperoleh CNSL dengan karakteristik BJ $=1,0107 \mathrm{gr} / \mathrm{ml}$, Viskositas $=2,7511$ poise , angka Iod $=242,9320$, Angka asam $=$ 15,4781 , Kadar resin $=11,2867 \%$, minyak yang diperoleh 8,5747 gram.

2. Untuk penambahan oksidator $\mathrm{K}_{2} \mathrm{Cr}_{2} \mathrm{O}_{7}$ yang paling optimal pada $12 \mathrm{mg} / 100 \mathrm{ml}$ CNSL dapat menurunkan kadar resin dari 11,34\% w/w menjadi 8,10\% w/w , dan Angka Iod naik dari 242,89 menjadi 250,82

\section{Ucapan Terima Kasih.}

Pada kesempatan ini penulis mengucapkan terima kasih kepada Muhammad Saleh yang telah membantu dalam analisis.

\section{Daftar Pustaka.}

AOAC, 1970, "Official Methods of Analysis of The Association Analytical Chemists ", Assosiation of Analytical Chemists , Washington D.C.

Bailey, E.A., 1951, "Industrial Oil and Fat Product", $2^{\text {nd }}$ ed, pp. $81-160$, Intercience Publisher Inc. New York.

Gardjito, M. dan Supriyanto, 1987, “Teknologi Pengolahan Minyak “, PAU Pangan dan Gizi, UGM, Yogyakarta.

Muljohardjo, M. 1990, "Jambu Mete dan Teknologi Pengolahannya”, 1ed, Liberty, Yogyakarta.

Ohler, J.G, 1986, “ Cashew Nut Processing “, Tropical Abstracts, vol .21, New York.

Prastowo, 1976, “Penelitian Tentang Peningkatan Mutu Minyak Laka” , Balai Penelitian Semarang.

Sudarmadji , S. dkk, 1976," Prosedur Analisa Untuk Bahan Mkakanan dan Pertanian" Bagian Pengolahan Hasil Pertanian, UGM, Yogyakarta. 